\title{
Las verdades ficticias en la otra escena de Dora
}

\section{The fictional truths in the other scene of Dora}

\author{
Mario Orozco-Guzmán*1 \\ Hada Soria-Escalante*2 \\ Jeannet Quiroz-Bautista*3
}

\begin{abstract}
El trabajo consiste en dar cuenta de cuatro posicionamientos de verdad ficticia derivados del drama de Sabina Berman, Feliz Nuevo Siglo doktor Freud, en torno al caso Dora de Sigmund Freud. De esta puesta de escena inherente a la estructura histérica se revelan los fantasmas de prostitución, de la seducción del padre, de la instauración de la feminidad y de la diversidad textual de la (contra) transferencia. El drama lleva la clínica a una dimensión de debate crítico donde el mismo Freud se encuentra dividido entre las formulaciones de su teoría sexual y las cuestiones inéditas que provoca el testimonio de la experiencia singular. No sólo se abre el telón de fondo de las condiciones sociales e históricas que enmarcan un ejercicio de clínica de la palabra y la subjetividad sino aquellas que determinan las complejas relaciones entre los sexos y los esquemas imaginarios-ideológicos que inciden en el pensamiento de Freud.
\end{abstract}

Palabras clave: Verdad-ficción, prostitución, seducción, feminidad, transferencia

*2 Universidad de Monterrey (Monterrey, México). 


\section{Introducción}

Entre la clausura del siglo XVII y principios del siglo XIX el pensamiento médico aproxima de manera fascinante la histeria al sexo, al enigma de los placeres femeninos y la constitución de mujeres cuya nerviosidad lleva a pensar en un exceso de voluptuosidad. La histeria se encuentra en el peligro de hacer enloquecer por 'l'abus d'excitation" (Corbin, 2005, p. 160). El cuerpo de la histeria es la culminación de las locuras del sexo. La violencia que sacude el cuerpo parece remitir a las pasiones inconmensurables de la sexualidad de las mujeres, que intimida e intriga al saber médico: "Este mal, que pesa tan abrumadoramente sobre las representaciones de la mujer, desde el fin del siglo XVIII hasta el triunfo de las teorías freudianas, se da esencialmente a ver como una retórica del cuerpo, 'atravesado de instintos y pasiones" (p. 179).

Charcot hace de su clínica un teatro de la posesión del cuerpo por la locura enigmática del sexo encarnada en la histérica. El pintor André Brouillet condensa la enseñanza de Charcot en un cuadro propio de un drama teatral. La personaje principal, Blanche Wittmann, "fue utilizada para efectuar frente al público de las sesiones clínicas la brillante demostración de los diferentes estadios de la hipnosis y de las crisis epileptoides, que se podrían desencadenar por el simple tacto de sus dos "zonas histerógenas"” (Pérez-Rincón, 1998, p. 29). Una mujer es utilizada como paradigma de un presunto saber médico sobre el cuerpo y la excitabilidad corporal de las mujeres. Este saber es el que parece requerir un espacio teatral. Se trata de exhibir un supuesto dominio, de hombres que saben sobre el cuerpo de mujeres, a su vez dominado, enloquecido, por la sexualidad. Como una teatralidad de la verdad del inconsciente del sexo desenfrenado.

Freud sustituye el testimonio visual por la actitud de escucha del sufrimiento histérico. Abre un espacio para que las palabras evoquen y convoquen experiencias que son traumáticas porque no 
hubo modo para que las histéricas apalabraran la impresión de abuso vivido en su infancia. Las palabras hacían representable un escenario de signos del ataque sexual cometido por un adulto. Escribe La interpretación de los sueños (1900/2006b) para mostrar al inconsciente en términos teatrales. Se adscribe al planteamiento de Fechner sobre la vida onírica como otro escenario, distinto al que rige el funcionamiento de la vida despierta. En sus conferencias de "Introducción al psicoanálisis" (1915-1916/2006h) recurre al sueño de "tres localidades de teatro a cambio de un florín y 50" (p. 206) para ilustrar el proceso de elaboración del sueño. El sueño le permite asir la participación de lo simbólico, de lo metafórico, para colegir el cumplimiento de deseo en los sueños, que se ciñe a la satisfacción de la pulsión voyeur y se cristaliza sublimatoriamente en poder ir al teatro. ¿A qué teatro? Para Freud se trata de la escena primaria, que anuda violentamente el deseo con la prohibición bajo el empuje de la curiosidad, donde el ver se enlaza al saber: "muy probablemente una ramificación de la curiosidad antigua de averiguar por fin lo que pasa cuando uno se casa. Como es sabido, esta curiosidad se dirige en los niños, por regla general, a la vida sexual de los padres" (p. 206). El teatro pondría al alcance lo que tanto se anhela ver y saber. El teatro es paradigma de la satisfacción de un deseo hecho de empuje epistemofílico.

Freud (1901-1905/2006c) pensaba titular "sueños e histeria" a su estudio clínico en torno a Dora, una adolescente con padecimiento histérico. El papel de los sueños suministra algunas claves, la otra escena del deseo inconsciente, para descifrar sus síntomas. Pero también el cuerpo cobra función escénica para hacer saber algo de lo reprimido sexual en juego. Lo inconsciente requiere un escenario para dramatizar los deseos que el yo de la persona desconoce y que remiten a la infancia. La histeria hace del cuerpo lenguaje del inconsciente, articulando lo inconciliable de representaciones emanadas de lo real-sexual del cuerpo. La histeria eslabona psiquismo y cuerpo en su puesta en escena capaz de reproducir fantasmas de opresión sexual. Sabina Berman, periodista y dramaturga, escribe en 2001 una obra de teatro para escenificar el drama y los conflictos subjetivos e intersubjetivos de Dora. En ese mismo año se presenta la obra en la Ciudad de México. Si "toda verdad tiene una estructura de ficción" (p. 22), como señala Lacan (1959-60/1990c), habría que detectar qué verdades se filtran en esta otra escena del caso Dora. La obra se denomina Feliz nuevo siglo doktor Freud. Se puede afirmar que ofrece, desde una lectura literaria, un esfuerzo de Überdeutung como Freud lo entendía para el desciframiento de los sueños. Esfuerzo correlativo al de sobre-determinación factorial de éstos y los síntomas. 


\section{La verdad-ficción del fantasma de la prostitución}

Jugando con la ficción, Octave Mannoni (1980) ya había creado un escenario de supuesto intercambio epistolar entre Dora y Frau K. Las cartas puntualizarían lo que Freud parece no haber atendido ni entendido. Mannoni habla de personajes imaginarios, para indicar lo imaginario en una relación de alteridad hecha de devoción amorosa. Este amor Freud sí lo habría adivinado, y por eso Dora lo perdona; pero no le perdonará no haber hecho "ningún caso de él” (p. 23). Mannoni pretende darle verosimilitud histórica a esta relación epistolar al fechar la misiva como primero de enero de 1906. Pone en relación a estas mujeres en torno al doktor Freud. En su carta Dora le dice a Frau K. que han transcurrido cinco años de la publicación del caso. Dora enfatiza, a partir de la manera en que Freud nombra el caso, su condición de don sacrificial. En esa posición podría haberle colocado el padre no sólo entregándole al tratamiento con Freud sino a la relación con Herr K.: "Pues bien, cuando le dije que se me trataba como un objeto de trueque, como moneda de canje, que me entregaban a él, por no haber podido entregarme a cualquier otro" (p. 15). Mannoni recoge las palabras que Freud dice haber escuchado de Dora cuando se refiere a su posición mercantil, entregada a Herr K. "als Preis für seine Duldung der Beziehung zwischen Doras Vater und seiner Frau" (Freud, 1901-1905/1999c, p. 193), como precio por su tolerancia a la relación entre el padre de Dora y su mujer, como objeto de intercambio. Freud advierte la Falschheit (p. 192), falsedad, del padre horrorizado ante la denuncia de su hija. Por otro lado, no cuestiona la complicidad y complacencia del padre ante el evidente asedio, incluso acoso, emprendido por Herr K. El padre de Dora simula que no hay nada entre él y Frau K., sólo una amistad fundada en sus propias desgracias. Y Herr K. también podría simular que no había interés amoroso en su acercamiento a Dora. Es un intercambio de falsedades.

Berman (2001) dramatiza este förmlichen Pakt, pacto formal, entre Herr K. y el padre de Dora, no admitido ni reconocido, estableciendo una posición identificatoria denigrante a través de la palabra de Dora, entre ésta y Frau K. El drama configura una confrontación y reclamo al padre:

Dora: te conviene creerle a él, porque tú y ella son amantes.

Herr F.: tenemos una amistad honorable, hija. Yo y Frau K. y su esposo.

Dora: Ja. Y ahora tú y el marido están de acuerdo en un precio por su mujer.

Herr F.: ¿Qué precio?

Dora: Tu hija. Yo. Él quiere usarme como tú usas a su mujer. 
Herr F.: Qué idea delirante. Monstruosa. (Tose)

Dora: Yo seré su puta como ella es la tuya. (p. 19)

El padre, Philipp Bauer, según la indagación histórica de H. Decker (1999), ha prostituido a Dora. Los dos caballeros han pactado un acuerdo para prostituir falseando sus propios intereses gozosamente narcisistas. Y Freud es cuestionado sobre su participación, como dice Lacan (1955-56/1990b), en este "odioso cambalache" (p. 207) en la medida en que el padre le demanda hacer entrar en razón y atraer a Dora hacia un mejor camino, pues el que ha tomado ella ha sido el peor, el más horroroso, haciendo del padre un monstruo. Dora se ha propuesto salirse de la escena (Lacan, 1962-63/2008) del intercambio de putas, infundiendo el horror en su padres con el suicidio. Lleva a una condición de exigencia de ruptura tanto con Herr K como con Frau K. Dora ha puesto a su padre en la encrucijada mortífera de elegir entre ella y Frau K. Traerla al mejor camino sería auspiciar que Dora participe de la falsedad y deje caminar la relación de amantes que sostiene su padre con Frau K. Pero también implica que deje avanzar el cortejo de Herr K. De allí que Lacan (1951/1990a) cuestiona en qué medida Freud "¿irá a mostrarse tan hipócrita como el personaje paterno?" (p. 207).

Berman quizás contradiga con su ficción-teatral la idea de Decker (1999) acerca de que Dora no habría asumido una postura de rebeldía, o no hubiera recurrido a su cuerpo para exponer su oposición al pacto de prostitución. Decker indica que Freud pudo promover una conformidad masoquista correspondiente a un ideal femenino vigente en esa coyuntura socio-histórica, sustentado en la disponibilidad gozosa a la enfermedad. Èl estaba de acuerdo con un arreglo interfamiliar viendo propiciatorio el enlace conyugal entre Dora y Herr K. en concordancia con una mayor libertad de vida de amantes del padre y Frau K. El ideal femenino es forjado a conveniencia del estatuto fálico de los hombres, para favorecer sus pretensiones de disfrute narcisista. En tanto putas, Dora y Frau K., abren la ruta de los deseos de desafío y transgresión en estos hombres. Freud (1912/2006f) había trazado la división en la vida amorosa de los hombres entre las tendencias sensual y tierna. El respeto a la mujer inhibe el deseo sexual mientras su degradación hace que el hombre despliegue "su potencia plena" (p. 179) poniendo en juego "componentes perversos". Eso es lo que sucede con el padre de Dora y Herr K., según Berman. La puesta en escena plasma de manera contundente un fantasma de prostitución. Este fantasma es discernido por Israël (1979) en el síntoma de vértigo y como forma de procaz vinculación con la fobia: 


\section{ARTIGOS}

Cuántos fóbicos no salen de su casa por este mismo temor a caer, a caerse, en la acera; la caída, la acera: la idea de la prostitución no está lejos. Temor, deseo, miedo de ser tomada por...todas estas imágenes se encuentran presentes en lo que se llama fantasma de la prostitución, que es uno de los significados "escondidos" dentro del "vértigo" histérico. (p. 33)

"Dejar caer" (Lacan, 1962-63/2008, p. 128) sería propio del pasaje al acto suicida. Dora parece dispuesta a dejar caer su posición de sujeto en este escenario de falsa seducción, de falsedad seductora. También remite a la caída de los primeros padres, a la pérdida de su pureza (Graves \& Patai, 2009), y a la caída de Eva en el pecado. El vértigo que invoca la tentación ratifica a la histeria como "enfermedad de metáfora" (Rosolato, 1979, p. 302). Tanto Herr K. como Freud denigran a Dora, la prostituyen, en la versión de Berman, en la medida en que no responde a sus apuestas y demandas. En el caso de Herr K. la expresión degradante enmarca la famosa escena del beso en la tienda; determinante para la eclosión del síntoma de la tos. Berman (2001) despliega una ficción en torno al supuesto régimen imaginario soporte del síntoma:

Herr K.: Qué dulzura. Dora, qué dulzura. Estoy perdido, por ti, perdido... (Besa a Dora en los labios largamente, estrechándola contra sí.)

Dora: Sentí contra mi cuerpo su...

Freud: Su miembro masculino.

Herr K. le toma la mano y la lleva a su pene.

Herr K. : Por favor...

Dora: No. No. (Un tercer no se le convierte en tos.)

Herr K. trata de besarla otra vez, ella lo abofetea. Retrocede caminando de espaldas muy despacio hacia el área de Freud.

Herr K.: Pequeña Zorra.

Dora: Salí corriendo. Me latía el corazón muy fuerte y tosía.

Freud: (A nosotros) En plena histeria. (p. 43)

Berman convierte a Freud en testigo visual de la escena del beso traumático cuando Dora tenía 14 años. En ella el beso se prolonga, Herr K. hace que Dora toque su miembro erecto y le ruega a ésta permitir su arrojo sexual. Ella expresa en dos ocasiones un "no" para impedir que Herr K. avance. El tercer "no" deviene síntoma de conversión histérica, lo que lleva a pensar en algo distinto al célebre desplazamiento de la excitación sexual de los genitales hasta la garganta, de acuerdo a la explicación de Freud. Consciente y deliberadamente Dora asumía una postura de rechazo a estas maniobras sexuales. Como Herr K. no se detiene ante las negativas verbalizadas de Dora el tercer "no" se articula como síntoma, se convierte en tos. Lo que se desplaza es la 
palabra, este "no", que no es escuchada ni respetada por Herr K. Dora abofetea a Herr K., como lo hará en la célebre escena del lago, porque ni siquiera su "no" convertido en síntoma es asumido. Sin embargo, consigue retirarse y se va con Freud. En ese momento, Herr K. la acusa de puta. Para él es insultante que una mujer no acepte sus envites sexuales y prefiera irse con otro.

Si la neurosis es el negativo de la perversión como Freud (1905/2006d) lo enunciaba, en esta escena se deja claro que la histeria encarna el "no" a la perversión del otro. Tanto que, al final de la obra de Berman, Herr K. se encuentra con Dora en un tren, y le dice: "Tú eres mi inocencia...Yo te amo con la inocencia de tener 17 años. Como tú. Eres mi última oportunidad de amar así, con simpleza" (p. 79). Es factible que refiriéndose a la inocencia infantil sucumba a la confusión de lenguas que señalaba Ferenczi (1984), y que involucre la pasión sensual en el anhelo de ternura. Herr K. le expresa su anhelo de ayudarle a estudiar y protegerla, Dora renueva su rechazo. Los reiterados "no" son interpretados por Herr K. como insultos. Herr K. la viola penetrándola con un dedo, escena parecida a otra donde el Sr. K somete sexualmente a su mujer de idéntica manera. Como si no tuviera otro modo de llevar a cabo el acto sexual sino éste que supone un categórico "sí", de voluntad perversa, "promoviendo el terror y el miedo" (Velázquez, 2013, p. 117). En función de esta promoción de angustia se alimenta el goce sádico de Herr K.

El grito de Dora durante la violación es absorbido por el silbato del tren. Nadie ha escuchado ese grito como nadie parece haber escuchado a Dora. Incluido Freud. La palabra "no" es imposible de escucharse por hombres que sustentan la creencia de que las mujeres tendrían que someterse o prestarse a sus designios sexuales. Velázquez (2013), explica que cuando "la mujer dice 'no' porque no desea tener sexo, su pareja puede interpretarlo como una provocación o desobediencia y sentirse con derecho a imponerse y a no tomar en cuenta la negativa" (p. 115). En una dimensión ideológica pero delirante, al hombre le asistiría un derecho a imponer su deseo a su compañera, o a la que concibe como 'su' mujer. Atribuyéndose derechos de propiedad y dominio sobre su cuerpo y vida; y a la cual no reconoce el derecho de ser sujeto y decir no. Por eso para las histéricas de Freud lo que generaba conflicto y rechazo eran sectores del cuerpo donde el deseo del perverso y de lo perverso imaginario del sujeto, se anclaba, y no había manera de ponerle palabras a ese anclaje perturbador. Israël (1979) menciona que la histérica corta la voz "entre la cabeza y el tronco" (p. 31), excluyendo el discurso y plasmando en el cuerpo el corte o fisura del deseo del Otro. 


\section{ARTIGOS}

Berman pone en el drama de Dora un fantasma de violación. Freud (1908/2006e) había descubierto en el ataque histérico una puesta en escena de un ataque sexual. El síntoma era una actuación de dos papeles; el del atacante, hombre violento que quiere arrancar las ropas de la mujer y su voluntad, incluso su inocencia; y el de la mujer atacada, empeñada en hacer respetar su intimidad y su palabra. La degradación es parte del discurso de Dora, en el drama teatral, para referirse a Frau K. De modo denigrante se refiere a ella cuando le hace saber a su padre, en su carta suicida, que éste desea su muerte. Si lo plasmado en la histeria es el circuito metonímico de desear el deseo del Otro, la clave es el deseo del padre de Dora por Frau K.: "La sra. K es el objeto de deseo de Dora porque es el deseo del padre, el deseo tachado del padre" (Lacan, 1957-58/1999, p. 376). Si Dora le supone a su padre el deseo de su muerte, entonces su disposición suicida se inscribe en ese circuito metonímico como una vertiente sacrificial. Con su muerte, todo se resolvería para el padre, y se lo espeta: "Todo sería más fácil para ti y Frau K, esa puta" (Berman, 2001, p. 16). Después de esta contundente réplica e insulto, el padre la abofetea. Bofetadas que se reiteran en otra secuencia de la obra y que no figuran en el testimonio clínico. Éstas correlacionan con la que le arroja Dora a Herr K. después de que afirmara que su mujer no representa nada para él. El padre antes de acudir a la violencia, tose. El síntoma anuda la identificación imaginaria entre padre e hija. Identificación a la cual Freud (1921/1999d) refiere cuando indica tres modalidades de vínculo afectivo, el más temprano lazo afectivo con otro, y la formación del síntoma de la tos en Dora sella el desenlace edípico, siendo una forma de poseer al padre. La identificación tiene un papel restrictivo, un rol reducido al de "einzigen Zug" (p. 117), rasgo único, configurado y modelado por la tos del padre. Esta apertura a la satisfacción que sustenta el síntoma, llevó a Lacan a establecer el concepto de goce. Es lo que sugiere Stryckman (2019): 'Lacan ha nombrado 'goce' a esta ambigüedad de la satisfacción del síntoma producido por el exceso de excitación corporal y su expresión por el psiquismo" (p. 163).

El fantasma de prostitución se instala en el mismo Freud hacia el final de la obra, cuando Dora acude a sesión para despedirse. Freud molesto advierte en esta decisión la satisfacción de un anhelo de venganza. Berman (2001) muestra el grado de su afrenta narcisista:

Freud: (A nosotros.) Y ella, que dejaba pasar mis palabras como si fueran nubes, replicaba de pronto, casi al azar, pero siempre con agudeza cruel.

Dora: Tendrá que encontrar otro conejillo de indias. 
Freud: Pequeña zorra vengativa. (A nosotros). Lo pensé, no lo dije. Pequeña zorra vengativa. (p. 71)

Así deja abierta la cuestión sobre el derroche de goce en el fantasma de prostitución. Freud (1905/2006d) había destacado que en su oficio la prostituta plasma la "disposición polimorfa" de pulsiones inherentes a la constitución sexual infantil. Señala que en mujeres con aptitud para tal oficio, se podría localizar "la uniforme disposición a todas las perversiones" (p. 174). Ostentarían la habilidad para hacer a un lado los diques anímicos de la moral, el asco, la vergüenza y el dolor. Encarnarían el placer sin límite y la promesa del goce. Freud asocia la venganza con la prostitución. La venganza podría situarse como una satisfacción narcisista en alguien como Dora que se podría sentir explotada por la ciencia sexual de Freud. Así como una prostituta se siente explotada por quienes dirigen y tienen el poder del negocio. Lacan (1955-56/1990b) habría atinado al señalar cómo se despliega el fantasma de prostitución en Dora siendo explotada y vendida por su padre. Aparece el fantasma en el momento en que Herr K. deja de ser el soporte imaginario para Dora en la relación de a cuatro que le resultaba relativamente cómoda. Dejando fuera del circuito escénico del deseo a su mujer. Así, Dora "reivindica, afirma que su padre quiere prostituirla, y que le entrega al sr. K a cambio de mantener sus relaciones ambiguas con la mujer de éste" (p. 133).

\section{La verdad-ficción de la seducción paterna}

Berman (2001) muestra a un padre cuestionado por su hija y por los síntomas de ésta. El padre violento es señalado por Herr K. como quien habría inducido a Dora por el camino del saber sexual. La habría llevado al teatro a ver una obra de nombre La Ronda:

Herr K.: En una hora y media La Ronda narra ¿cuántas seducciones sexuales? Diez. Una cada siete minutos. (Mientras mira fijamente a su esposa:) Ni siquiera en un burdel hay tanto movimiento, te lo aseguro. (A Herr F.:) Si a nosotros nos excita La Ronda, nos excita y la imaginación se nos calienta, a la pequeña Dora la imaginación se le encendió en llamas de lujuria. En efecto, enloqueció: la enloqueció su padre. (p. 34)

Poner al padre a nivel de causa seductora para una hija que hace síntomas histéricos, conecta con la teoría freudiana del trauma. Para Freud la seducción del adulto perverso contra una criatura inocente, era crucial 
para entender el sufrimiento histérico. Responsabiliza por un momento al padre de la neurosis de la hija, pues la habría hecho enloquecer. Brun (2013) destaca esta indulgencia de Freud respecto a su padre como giro decisivo en su conceptualización sobre el funcionamiento subjetivo. Como si la exoneración del padre perverso transitara hacia su exaltación. Freud no cuestiona al padre en los casos de Hans y Dora. En Hans, la madre y su palabra no son tomadas en cuenta. Solo es cuestionada como posible instancia perturbadora por exceso de ternura o para denotar sus actitudes despectivas o amenazadoras hacia el sexo del pequeño. En Dora, la madre es denostada al estar atrapada por la locura obsesiva de la higiene doméstica. El elogio del padre de Dora es tan expresivo en el discurso de Freud que Mannoni (1980) hace decir a Dora, que el mismo profesor estaría enamorado de su padre: "No se interesaba en mí. Sino solamente por agradar a papá" (p. 17). En el afán de agradar al padre Freud lo agranda al exonerarlo o lo disculpa idealizándolo: "El componente histérico de los síntomas y producciones psíquicas de la chica ocupa en gran medida el relato, y Freud se cuida bien de emitir en cualquier momento la hipótesis de una responsabilidad psíquica del padre en la sintomatología" (Brun, 2013, p. 51). No obstante, Herr K. en el drama de Berman responsabiliza al padre de haber seducido a su hija llevándola a un escenario que representaba precisamente seducciones sexuales.

En esta inculpación es sorprendente la alusión al incendio provocado por las imágenes de La Ronda. El tema del primer sueño es un incendio. Berman (2001) hace decir a Freud que el "incendio es el sexo" (p. 64). En este incendio del sueño, el padre aparece engrandecido como salvador al despertar a Dora. La madre preocupada por salvar su alhajero resultaría responsable del daño que pueda derivarse. Sin embargo, es el padre el que ha dañado el joyero, los genitales de la madre, al contagiarla de su infección sexual. El que aparece como salvador en el sueño es el que ha puesto en peligro a Dora y la que aparece como poniendo en peligro en el sueño es alguien que se obstina en limpiar las excrecencias del sexo. Pero la situación de este "cuarteto" como Lacan (1956-57/1994) designa las relaciones entre Philipp Bauer, Frau K., Herr K. y Dora, es incendiaria, pasional. Hacia el final de la obra, Lou-Andreas Salomé, se posiciona transferencialmente en el lugar de Dora experimentando "una creciente falta de aire como quien tiene la premonición de ahogarse....y tosí" (p. 71). Freud también tose diciendo "Gesundheit", palabra que significa salud. Después de decir que hay "demasiado humo", pedirá perdón, ¿por haber participado en el incendio? ¿o por haber contribuido a su intensificación? Era un cuarteto que se sostenía saludable hasta 
que estalló el incendio con lo insultante que fue para Dora escuchar a Herr K decir que su mujer, una "schwärmerisch geliebte Freundin" (Freud, 1901$-1905 / 1999$ c, p. 222), amiga amada de modo exaltado, era nada para él. No se puede soportar un ambiente donde exista un interés exclusivo en el plano del deseo de una persona por otra persona. El deseo tiene que transitar por la mediación del deseo del Otro. Herr K., modelo y prototipo de identificación para Dora, no puede quererla dejando fuera de la Ronda del deseo a su mujer.

\section{La verdad-ficción de la cuestión femenina en Dora}

Frau K. ha sido también seductora incendiaria de Dora. También agitó el fuego proporcionándole los medios para entrar en la dimensión incendiaria del sexo. Encarna este saber sobre el sexo y la pregunta-respuesta sobre el misterio de la feminidad. Allí radica la investidura de Frau K.: "Es decir, no un individuo, sino un misterio, el misterio de su propia femineidad, queremos decir de su femineidad corporal, tal como aparece en el segundo de los dos sueños" (Lacan, 1951/1990a, p. 209). Freud (1921/1999d) propone cuatro dimensiones de la alteridad: la de objeto de apetencia sexual, la del enemigo en confrontación y rivalidad, la del colaborador en condiciones de solidaridad y apoyo, y la del modelo para establecer guía de confección ideal del yo, de identidad sexuada. Frau K. podría inscribirse sobre todo en la de modelo para forjar un advenimiento a lo femenino. Berman pone en escena un encuentro entre una mujer plena, y alguien que aspiraría a ser mujer. En el elevador se encuentran y Frau K. pulsa un botón. Es el botón para ascenso y acceso de Dora a la femineidad. Dora admite que esta mujer corta su aliento, el movimiento pulsional de su excitación oral, y evoca a su padre haciendo sexo oral a Frau K., lo que produce un efecto hipnótico en Dora mientras le pinta labios y mejillas. La seduce mientras la feminiza o la feminiza al tiempo que la seduce.

Freud (1921/1999d) ya había establecido un paralelismo entre hipnosis y enamoramiento, dado que en ambas experiencias el objeto promueve fascinación y servidumbre. El botón que pulsa Frau K. es el aliento del cuerpo deseante. Allí se localiza a Frau K. como objeto de deseo del padre y, luego de Dora. Objeto de aprehensión oral para alguien "chupeteadora" (Freud, 19011905/2006c, p. 46), aunque luego expulse la culpa a través de la tos. Esta fantasía de goce oral, Berman (2001) la pone en palabras de Dora exhibiendo su saber sexual ante Freud. Le dice que entiende que la impotencia de su 
padre no impide que pueda, con la sra. K, tener sexo "con las bocas" (p. 23). Freud había sospechado sin lograr corroborar en Dora un espionaje auditivo de la escena primaria. En la obra de Berman, Dora señala cómo pasarían del cunnilingus a la fellatio. Al exponer esto, irrumpe en Dora el síntoma de la tos bajo ese fenómeno que Freud había llamado Mitsprechen (Freud, 1893-1895/1999a, p. 30), contar, entrar en lo que se cuenta; haciéndose participe del discurso que se despliega en la cura. Incluso Freud, en la obra de Berman (2001), mandata a Dora: "Reprime la tos" (p. 36). Sorprende esta intervención donde se insta no tanto a descifrar el síntoma sino a reprimirlo. Dora indica cómo en esos episodios eróticos su padre ocuparía su imagen chupeteadora, interpretada por Frau K. como gesto de amabilidad. La potencia está en la boca, nada sincera del padre, en sus posibilidades de brindar goce a Frau K.:

La afonía aparece porque Dora es dejada directamente en presencia de la señora $\mathrm{K}$. Todo lo que pudo escuchar acerca de las relaciones de ésta con su padre gira en torno a la fellatio, y esto es algo infinitamente más significativo para comprender la intervención de los síntomas orales. (Lacan, 1955-56/1990b, p. 250)

Frau K. es para Dora su maestra de sexo. Ella suministra a su marido la información acerca de los saberes de Dora acerca del sexo. De este modo la despoja de su imagen de inocencia ante su padre, haciendo pesar sobre ella el velo de la sospecha. Frau K. en la escena de Berman, es la alteridad fundamental para la feminización de Dora, aunque ésta señale que no quiere ser mujer. Para Dora ser mujer se reduce a ser la sirvienta de los hombres. Como lo asevera Lou Andreas-Salomé: "siempre supeditada a los varones" (Berman, 2001, p. 44). Ser mujer consiste en encontrase como objeto sexual, siempre dispuesta a estar al ser-vicio de los hombres. Frau K. no es como su madre ni respondería a un ideal de maternidad. Por eso Dora se esfuerza en cuidar a sus hijos, haciendo "el papel de madre" (Freud, 1901-1905/2006c, p. 34). Frau $\mathrm{K}$. se desenvuelve en otro terreno de modo exuberante. Impone su deseo y hace disfrutar y enloquecer a su padre; el cual es maestro en sacar ventaja del síntoma. La tos sirve al propósito de estar con Frau K. Ella sabe hacer gozar a los hombres, incluso a los supuestamente incapacitados para el disfrute sexual. Freud entendía la oposición simbólica entre el enorme falicismo del dinero, "ein vermögender Mann" (Freud, 1901/1999b, p. 207), un hombre acaudalado, y el precario falicismo de la potencia en relación a su padre, "ein unvermögender Mann", un hombre impotente. El padre, modelo para forjar síntomas como expedientes para evadir toda responsabilidad, habría intentado quitarse la vida. Freud describe cómo Frau K. acude a salvarlo. Berman hace al padre 
suplicarle: "No puedo. No puedo vivir sin ti" (p. 35). Sólo Frau K. le proporciona la potencia necesaria para querer vivir y disfrutar el sexo. Por eso ella es lo que el padre desea de modo trascendente, más allá de Dora (Lacan, 1956-57/1994), marcando la condición de falta en ésta:

Así, el padre impotente suple por todos los medios del don simbólico, incluso los dones materiales, lo que no realiza como presencia viril, y de paso hace a Dora su beneficiaria, con una munificencia que se reparten a partes iguales su amante y su hija, de modo que lleva a participar en esa posición simbólica. (p. 144)

Dora misma obtiene ventajas secundarias, paradójicamente, de los recursos económicos de un padre sin recursos sexuales. También la madre obtiene algo con esta generosidad del padre para disimular los regalos que le hacía a Frau K. Parecía que todos ganaban en el negocio de intercambio de bienes sexuales. Pero el cuerpo de Dora, con sus malestares afónicos y la tos, dice otra cosa.

Frau K. da la impresión de tener el control de su vida y del deseo del padre de Dora. En el texto de Berman, Freud le expresa a Dora, cuando ella tiene 32 años, que ya no podrá atenderle. "Yo sinceramente, encuentro que lo que comprendo del desarrollo de la mujer es insatisfactorio y muy inseguro. Las mujeres me son - todavía - un misterio" (Berman, 2001, p. 84). La ayuda que le podría brindar una mujer analista ya se la suministraba Frau K., que se presenta como pregunta-respuesta a este misterio que también lo es para las mismas mujeres: "Dora se pregunta - ¿Qué es una mujer? Y eso porque Frau K. encarna propiamente la función femenina, porque ella es para Dora la representación de algo en lo que dicha función se proyecta como pregunta, como la pregunta" (Lacan, 1956-57/1994, p. 144).

En la obra, más que identificarse con Frau K., la imita. Hace como si fuera ella moviéndose de forma coqueta después de salir de esta escena del elevador. Dora esta hipnotizada por Frau K., quien tiene en sus manos el poder de seducir a los hombres, y de feminizar a alguien como ella atorada por la cuestión de en qué consiste ser mujer. Lacan (1955-56/1990b) retoma el mecanismo como sí, descubierto por Helen Deutsch en la clínica de la esquizofrenia, para dar cuenta de un proceso de compensación imaginario de un Edipo fallido. Berman pone en acto este como si en el gesto de Dora imitando a Frau K., imitando los movimientos coquetos de alguien poseedor de un "cuerpo deliciosamente blanco" (Freud, 1901-1905/2006c, p. 55).

Lacan (1955-56/1990b) señala que no es lo mismo preguntarse acerca de qué es ser mujer que devenir mujer. Convertirse en mujer exige la prueba 


\section{ARTIGOS}

de la castración. Y precisamente este proceso es el que Berman pone en escena haciendo que Freud lo ejecute acudiendo al bisturí. Tendrá que hacerlo después que Dora dice no a la interpretación sobre su supuesto anhelo erótico dirigido a Herr K. Freud no puede aceptar que Dora no acepte su interpretación. Es un signo de rebelión de una joven en posición/posesión fálica, una mujer en plena histeria o en la plenitud de desafío histérico. Como esas mujeres narcisistas que ya en "la pubertad se han sentido varones y durante un tramo se desarrollaron como tales" (Freud, 1914/2006g, p. 86). Freud, herido en su narcisismo, interviene a nivel del cuerpo de Dora, en lo real escenificado, en la medida en que considera que a nivel de su palabra no ha habido manera de establecer un corte significante que a Dora le hiciera entender cabalmente su pasión amorosa por Herr K. Lou Andreas-Salomé justifica la intervención:

Lou: Así que se había decidido por una cirugía mayor. (Freud regresa a tomar asiento junto a Dora. A nosotros.) Si la enfermedad de la mujer independiente es un falo imaginario, hay que cortar el falo.

Cuando Freud regresa a donde está Dora, la encuentra sobre una mesa de quirófano, una sábana cubriéndola. (p. 65)

Cuando llega a la pubertad, Dora se habría convertido en una mujer independiente capaz de confrontar y mofarse de los médicos con sus ataques de tos. Como si el síntoma se mostrara irreductible al afán médico, al amo del saber científico. Algo difícil de extirpar a menos que se recurriera a una cirugía mayor, en una equivalencia entre síntoma y falo imaginario. Freud (1901-1905/2006c) retoma la figura-modelo sintomatológico del hermano para Dora, de quien tomaba las enfermedades como ideal identificatorio, comportándose como él, como una "criatura salvaje" (p. 72). Hasta que interviene en lo real el asma para hacerla "tranquila y decente: la contracción de esta enfermedad marcó en ella la frontera entre dos fases de la vida sexual; de ellas, la primera tuvo carácter masculino, y la segunda, femenino" (p. 72). Una enfermedad socava su capacidad para hablar, y a la vez, la feminiza. Por eso Dora cuestiona a Freud, en el drama de Berman, queriendo saber por qué le quiere "cortar las alas". Lou Andreas-Salomé interviene remplazando alas por pene y potencia. Freud encara a Dora diciendo que su resistencia, que su "no a ser mujer debe ser sacrificado" (p. 67). Para convertirse en mujer debe renunciar al pene imaginario que le daba la potencia de volar en el sueño de un ideal viril. Una ilusión de plenitud imaginaria se ve mutilada pues Freud no deja de insistir en cuánta falta le hace a Dora Herr K. 
La cirugía mayor de Freud atraviesa el ser de Dora. La desposesión narcisista que produce es decisiva pues se puede indicar con Rosolato (1979) que "el histérico es el falo, que 'correría la riesgosa' aventura de tenerlo: he ahí su drama" (p. 294). La ambigüedad es tener al otro y/o tener su pene. También Berman propone el riesgo de perderlo, o perderse en tanto falo que cree ser. La infatuación tiene consecuencias: "Dora tiene la ilusión de llegar a ser completa, es decir de desplazar la falta. Otra mujer se le aparece como perfecta, la señora K. - la Madonna. Si la señora K no es nada para su marido, la ilusión cae estrepitosamente" (Torres, 1984, p. 94). Dora no puede concebir que quien es el resarcimiento de una madre decepcionante, sea nada para quien aparecería situado en el plano narcisista del Yo-Ideal. Frau K. parece saber mucho acerca del deseo de los hombres. Pero también se advierte la imagen de otra mujer, que no requiere sexo para tener hijos. La madre-virgen que sólo admite admiración extasiada. La cirugía mayor de Freud despoja a Dora de las alas de su falo imaginario y de pretender "erigirse en falo" (Torres, 1984, p. 98) para volar por encima de las diferencias de los sexos. Se detecta una transición metonímica que se desliza de hombres y mujeres que causan decepción en Dora a una mujer de excepción, Madonna. Frau K. es eslabón que posibilitaría esta transición.

\section{La verdad ficticia de la transferencia}

Dora está en oposición a lo que supone el deseo curativo de Freud. Antes de la despedida, Freud requirió de dos sesiones para descifrar el segundo sueño. Él le hace saber su beneplácito por lo que han podido avanzar. Ella lo cuestiona: "Was ist denn da viel herausgekommen? (1901-1905/1999c, p. 267), ¿Qué es mucho lo que ha salido a la luz? Empezará la tercera sesión usando la misma frase que empleó Herr K. para revelarle que su mujer no le importaba: "Wissen Sie" (p. 268), sabe usted. Como si el otro debiera saber que es inminente la ruptura. Por su parte, en el discurso de Herr K. se invierte la relación entre sujeto y verbo: "Sie wissen..." (p. 260), usted sabe. Le devuelve a Freud la frase que Herr K. le habría dirigido a ella. Lo que lleva a la problemática de la transferencia que Freud señala no haber atendido en la cura analítica con Dora. Se le supone un saber al otro sobre los designios del sujeto. Freud se refiere a este concepto hacia el final del texto en plural hablando de Übertragungen (p. 279), transferencias. Se deduce que transferencia no hay una, sino varias, diversas. Están hechas de lenguaje, son 
de hecho textos. Es esta comprensión de la transferencia en términos de texto lo que Berman pone en boca de Freud, aludiendo a cómo enlazamos diversos personajes de nuestro entorno presente con aquellos de relieve en nuestro pasado. El ajuste transferencial será en función del deseo hilvanado en la seriación repetitiva que produce una nueva realidad, la realidad de lo simbólico, introduciendo algo "neu" en el proceso, algo diferente:

Ella está ahí para hacer surgir, para recordar, para hacer insistir algo que no es otra cosa en su esencia que un significante, designable por su función, y especialmente bajo este rostro, que introduce en el ciclo de las repeticiones, siempre las mismas en su esencia, y entonces en relación a algo que es siempre la misma cosa, la diferencia, la distinción, la unicidad. (Lacan, 1961-62, Leçon du 20 décembre 1961)

El conocimiento del otro, en el drama de Berman, resulta engañoso al encontrarse atravesado por las transferencias. Desde éstas, conocer a un otro es algo equívoco y confuso. Es un fenómeno que Freud (1901/1999b) concibe como una "Neubildung von Symptomen" (p. 279), neo-formación del síntoma. Es decir, es también una reedición, y con este aspecto "neu" se plasma como una renovación, del síntoma también inteligible como texto.

Berman propone que Dora sería el caso de un Freud triplemente escindido en y por la comprensión de la dinámica transferencial. Un primer Freud señala la pretensión que tenemos acerca de conocer a alguien de quien no sabemos nada. La transferencia se inscribe como una experiencia de asociación libremente inconsciente entre nuestras "nuevas conocencias con personas significativas de nuestro pasado" (Berman, 2001, p. 26). El saber transferencial irrumpe y se anticipa al conocimiento gradual del otro. Impide que la conocencia resulte nueva y que el otro sea un extraño. Por eso, un segundo y tercer Freud se integran, e integran por la ruta del saber inconsciente de la transferencia, lo que es del orden de lo desconocido. Un primer Freud se pasea por el escenario disertando como científico. Un segundo Freud aparece para señalar que ha decidido poner al informe de este caso el nombre de Pandora. Un tercer Freud hace la crítica a esta designación que daría motivos para odiarlo por alardes de presunción. Entonces el segundo Freud corrige e impone el nombre de Dora. En el texto de Berman parece suscribirse la observación de Janet Malcolm (1981) acerca de la posible incidencia de la figura mítica de Pandora en la elección del nombre del caso. Decker (1999) se refiere a ella como primicia divina, como regalo confeccionado por Zeus para saciar su venganza contra los seres humanos ante la osadía de Prometeo robando el fuego divino. También Dora, de acuerdo a Decker en su pesquisa 
de una misiva a Fliess, sería regalo para un Freud inquieto por entender y descifrar desde la experiencia de cura el fenómeno transferencial. Pero si fuera esa la cuestión insospechada por Freud, en la elección del nombre, el drama de Berman haría consciencia de algo inconsciente. Habría que advertir que Pandora es una figura mítica que envuelve una autentica paradoja de orden ético. Plasma en su hechura misma la presencia ostentosa de bienes y males, así como contención y diseminación de las calamidades que destinaría Zeus a los humanos en su operación vindicativa. Si esta fuera la egregia referencia para la determinación del nombre, como lo indica el texto teatral, Dora sería más bien el producto de la mutilación de un significante que condensa la idea del todo "Pan", con la idea del don, "Dora". Se preserva en el nombre la remisión al don, el regalo, y quedaría excluida la referencia a la plenitud. Es el llamado a la modestia que invoca el tercer Freud al segundo Freud que podría enaltecerse al denominarle Pandora al caso. El llamado de la castración.

La triple Spaltung de Freud, en la escenificación de lo transferencial diversificado, aparece en diversos momentos. En un momento desarrolla este trío un coloquio a partir de la aseveración lanzada por Freud 2 acerca de cómo es imposible negar y escapar al fenómeno de la transferencia. Freud 3 le hace saber que de esto se reclamarán evidencias científicas:

Freud: Es claro que en un principio del análisis yo fui colocado en la imaginación de Dora en el lugar de su padre. (Freud 2 y Freud 3, que se cala los lentes gruesos que lo convierten en Herr F., se ponen en píe; se mueven de manera idéntica mientras Freud ha continuado sin pausa alguna.) Asociación consciente en ella, y por lo demás acertada, dadas las semejanzas entre el padre y yo:

Freud 3: semejanzas en nuestra edad, nuestro aspecto físico, nuestros ademanes

Freud 2: adquiridos en un milieu similar

Freud: El hecho de que ambos fuéramos judíos. (p. 28)

Freud (1901-1905/1999c) se colocó imaginariamente en el lugar de este "Grossindustrieller" (p. 176), impotente sexual pero persona dominante y con actividad y capacidad especiales. “¿Cómo no colocarse en este sitio si su padre, Jacob Freud, resultó ser "comerciante pobre, optimista incurable, ineficiente, mercader en lana, incapaz de enfrentar el nuevo mundo industrializado?" (Rodrigué, 1996, p. 55). Decker (1999) transmite lo relevante para Dora del logro económico de su padre en un "milieu" sumamente adverso. Berman expone la contratransferencia de Freud ante los enigmas del deseo y la identificación en Dora. La asociación entre Freud y su padre 


\section{ARTIGOS}

sería consciente para Dora pero no tanto la asociación entre el padre de Dora y su propio padre para Freud. ¿Qué hay de nuevo en la relación que se establece con Freud? ¿Qué podría cambiar? Quizás que Freud sí crea en su palabra, y no la use para satisfacer intereses egocéntricos de otros y de él mismo. ¿Podría Freud ser alguien con la autoridad suficiente para no engañar ni dejarse engañar por los deseos del padre y de Herr K.? ¿Podría entender que si Dora quiere venganza es porque hay odio en suspenso? Este odio no fue suficientemente apalabrado, quedó restringido en su anudamiento simbólico. Es el odio que se sacia en la venganza. ¿No debería entenderse que ella es una adolescente con todas las incertidumbres y angustias en relación con su cuerpo y su deseo? Lo nuevo es propiamente el odio de adolescente, odio en relación con ambos padres. Odio silencioso o silenciado en Dora que precipitará su salida del compromiso analítico. Ese es el componente de un saber transferencial que ensombrece toda "conocencia" y que evidencia en Dora su impresión de ser objeto de un experimento por parte del Doktor Freud, "conejillo de indias", atendiendo y confirmando sus presuposiciones teóricas e interpretaciones contundentes ¿Cómo no experimentar odio hacia este hombre que parece abierto a lo que ella pueda decirle sin tapujos y al mismo tiempo tan cerrado como para imponerle la supuesta verdad de su enamoramiento por Herr $\mathrm{K}$ y la condición de ser mujer? ¿Este odio acaso no se denota en el drama de Berman tanto en el momento en que Dora le asigna a Freud una condición de empleado de su padre al decir que éste "le paga para que "nada le pase a su familia"” (Berman, 2001, p. 24)? Berman muestra a una Dora incisiva y corrosiva haciéndole notar a Freud sus carencias, en comparación con la familia de su padre sumamente rico. La esposa de Freud está obligada a labores de limpieza en casa porque "no tienen sirvientas" (p. 22). Este odio que ansía el "envilecimiento" (Lacan, 1953-54/1981, p. 403) del otro, es quizás a lo que responde Dora, al final del drama teatral, con una petición de perdón dirigida a Freud. Admite hacia el final que la "soberbia" (Berman, 2001, p. 85) le hizo fallarle a Freud, a su padre y a sí misma. Si Lacan (1953-54/1981) afirma que "la transferencia es el amor" (p. 142), tendríamos que agregar que lo es también el odio, en tanto ambos se confunden como Lacan mismo lo enfatiza en la dimensión imaginario-pasional.

Lauru (2015) menciona que el adolescente pasa por facetas de odio, oscilando entre ponerlo en palabra y en acto contra el otro o contra sí mismo a falta de "support d'identification" (p. 57) por parte de los adultos. Dora creía contar con Herr K. para este soporte identificatorio. En la obra se pretende 
hacerlo valer por parte del padre como un "tío cercano" (Berman, 2001, p. 17) para ella, lo que haría que sus acosos y violación adquiriesen el sentido de incestuosos. Berman propone una asociación entre Dora y Ana Freud. Es un lapsus lo que delata este enlace, esta "falsche Verknüpfung" (Freud, 1893-1895/1999a, p. 309), vinculación falsa, que así es como Freud se refería a la transferencia en sus trabajos sobre la histeria. Se produce cuando Ana Freud le lleva la cena a su padre que se encuentra en el consultorio acompañado de sus partenaires:

Freud 3: Precisamente por ello habría de enseñarme mucho más sobre los procesos sanos de la mente.

Ana: Papá

Freud 3: Tales como la transferencia

Freud: (Alzando despacio el rostro.) Si, Do...

Freud 2: ¿Do...? ¡Dora!

Freud 3: No, Ana. Ana.

Freud 3 y 2: Lapsus lingüe, lapsus lingüe. (Berman, 2001, p. 29)

Hay un Freud, sujeto del inconsciente, que a medias emite el lapsus. Los otros dos hacen acopio del saber del inconsciente para dar cuenta de esta derivación auténtica del deseo. Berman (2001) descubre las vinculaciones intergeneracionales de la transferencia, una perspectiva inédita, por las que Freud habría visto "a Frau K. a través de su esposa Marta, a quien veía a través de... su madre quizá; vio a Dora a través de su hija Ana y a Ana a través de quién sabe quién" (p. 70). La relación con su hija estará atravesada por la experiencia con Dora. Dora será para Freud la maestra de la transferencia. Hace reinar su deseo insatisfecho ante su padre, el señor K y Freud. De ahí deriva la propuesta del discurso histérico: "La apuesta consiste en producir un saber, este: el amo es un hombre castrado [...] Así, la histérica encarna por sus propios síntomas ese rechazo del cuerpo" (Julien, 2002, p. 180). Dora, emblema histérico, encarna este rechazo de los amos aunque parezca buscarlos. Son ellos los que parecen requerir de su sostén. Como lo vemos en el padre de Dora y Herr K. ¿Freud no parece requerir de Dora para sostener su teoría?

Berman (2001) introduce el acontecimiento de un modo distinto de ser mujer. Una mujer que no sea como la misma hija de Freud que pregunta a su progenitor: “¿Qué te sirvo, papá?” (p. 48). Dora se despedirá como se despiden estas mujeres que están para servir. Cuando Freud (1901/1999b) piensa en qué nombre asignarle a la joven cuyo caso está por publicar evoca a la empleada doméstica de su hermana Rosa. Es la vicisitud biográfica que explica desde otra escena la determinación del nombre del caso. Dora sería 
en este caso no producto de cercenar el ilustre nombre de Pandora, sino emblema de un acto de conmiseración. Freud se expresa de modo bedauernd (p. 269), compasivo, apiadándose de personas que parecen no tener ni el derecho de conservar su nombre ¿Qué tipo de com-pasión habrá suscitado Dora en Freud? ¿A través de qué otro u otra estaría viendo Freud a Dora? ¿No es también otro tipo de sacrificio el que una persona deba renunciar a su nombre propio supeditándose a las exigencias e intereses de un otro que representa un lugar de poder y autoridad para ella? De igual manera, en Pandora nos encontramos con un personaje que sólo responde a los intereses malignos de los dioses contra los hombres. Es el regalo nefasto. Pandora carece de voluntad propia, pues fue creada como instrumento de engaño. Dora, por su parte, se encuentra inscrita en una especie de intercambio de regalos entre hombres, de objeto mercantil para extraerle plus-de-goce. Pandora, Dora, y la niñera de Rosa Freud, son objetos-sacrificiales en manos de quienes ejercen poder. La misma Frau K, estando presente Herr K, le implora al padre de Dora: "No sacrifiques a la niña (Herr K. se lleva la copa a los labios). Ella no tiene la culpa de nuestros enredos" (Berman, 2001, p. 33). El mismo ruego podría haberle expresado Prometeo a Zeus señalando que Pandora no tenía la culpa de sus enredos ¿Lo que se está sacrificando en Dora, al designarla como niña, no es la posibilidad de autonomía, la esperanza (para evocar el mito de Pandora), de libertad? Berman podría tener presente una interesante reflexión de Lou Andreas-Salome (2013) sobre la difícil conquista de autonomía en las mujeres, donde se confunden "con un anhelo orgulloso y varonil de querer liberarse a costa de los restantes aspectos de su ser" (p. 30), encontrándose en la disyuntiva de ser como el hombre y salvarlo, o ser "un simple medio para que éste logre su autonomía" (p. 30).

No se trata de una autonomía al estilo viril o una donde se subordine a la que los hombres ostentan. Tampoco de las supuestas autonomías de la maternidad que confiere un supuesto poder imaginario de ley caprichosa (Lacan, 1957-58/1999). Lou Andreas-Salomé señala en la obra que Dora no querría ser una mujer supeditada a la voluntad narcisista y patrimonial de los varones. Cuestionando a su 'padre intelectual', Lou se dirige a nosotros y a un mundo que niega a las mujeres la posición de ser sujetos de deseo y sujetos de ejercicio político: “¿Por qué usted, que ha visto más allá de su propia cultura en tantas cosas, aquí no puede ver más allá?, ¿qué tal que Dora es una nueva mujer?" (Berman, 2001, p. 51).

Es posible que lo "neu" de la vinculación transferencial sea la reedición del texto de una mujer que problematiza las relaciones con el deseo y el 
cuerpo, con el sexo y la femineidad. Freud nombra histeria a todo aquello que va contra lo esperado por el amo del saber científico, el amo del saber sobre el sexo. ¿Cómo alguien, en lugar de responder con placer al placer del otro, lo hace con displacer o angustia? Debe ser una mujer cuyos "sentimientos están del revés" (Mannoni, 1980, p. 19), una mujer que propone el reverso o la subversión del orden afectivo en las relaciones de alteridad que, en última instancia, es propia del universo del lenguaje. Para Freud es posible que la experiencia de Dora le permita entender a la transferencia en su condición de acto abrupto, como "la puesta en acto de la realidad del inconsciente" (Lacan, 1964/2013, p. 152). Por eso para Berman el historial de Dora era transferible al teatro, como puesta en escena de los impasses del deseo en sus relaciones de alienación con el deseo del Otro.

Esa transferencia al escenario teatral pasa por la puesta en texto de algo de orden inconsciente ¿De qué trama textual estaríamos hablando? Es la trama que pone el "plano de la afirmación de la verdad" (Lacan, 1951/1990a, p. 207) a través de la hipocresía, de la falsedad. Freud es interrogado acerca de en qué medida será igual de falso que el padre. Berman (2001) hace decir a uno de los tres Freud su disposición a no dejarse subyugar por "la hipocresía" (p. 14) de la cultura de su época acerca de la sexualidad. Lo que está en juego en la transferencia en Dora es la relación con la falsedad y, por tanto, con la autenticidad. Freud, se refiere a la transferencia como un enlace falso con el analista. Pero ya había advertido que para la interpretación de los sueños era indispensable que el sujeto desplegara enlaces que podrían ser engañosos entre las ocurrencias vertidas. Ejemplificaba la apertura asociativa con la serie de nombres que sustituyen al nombre verdadero en el caso de olvido de nombres propios. Los nombres que acuden y que resultan falsos conducen al "genuino" (Freud, 1915-1916/2006h, p. 101). El camino hacia lo verdadero pasa por asociaciones falsas, por el proceso de asociar que también significa, según lo propone Dora en el drama de Berman (2001) emprender un "salto de tema” (p. 22) ¿Un salto de lo falso a lo verdadero?

\section{Conclusiones}

Para Freud (1900/2006b), el aparato psíquico poseía una estructura de "ficción" (p. 587) o se postula como una "ficción teórica" (p. 592 ) para establecer "conjeturas" (p. 530) en torno a su funcionamiento primordial para eximirse de estímulos. Es indispensable apelar a esta otra escena para 
develar la verdad del deseo que se cumpliría por la vía engañosa de lo real alucinatorio. Aunque Freud (1892-1899/2006a) ya había advertido que en la aprehensión de lo inconsciente no es posible diferenciar "la verdad de la ficción investida de afecto" (p. 302), Berman plasma verdades ficticias investidas de deseo donde se cierne un saber conjetural. Para que las conjeturas se delimiten y no sucumban, como Freud lo indica, a una confusión entre los andamios y el edificio, hemos anudado revelaciones de la obra con conceptualizaciones formuladas y discernibles en torno al caso. Así tenemos la posibilidad de abrir un espacio de deconstrucción del caso a partir del texto dramático. Las conjeturas sobre el fantasma de prostitución hecho montaje teatral remiten a lo que Freud (1892-1899/2006a) develaba al señalar la posición identificatoria en la histeria con "personas de nivel moral inferior" (p. 289). Freud localiza una "angustia de prostitución" (p. 290) que se presenta en las mujeres de servicio doméstico. La línea de ficción de la seducción paterna plasmada en el escenario de Berman ilustra lo que el mismo Freud (1915-1916/2006h) había develado respecto a cómo el deseo de los padres se plasma en tanto "incitación" (p. 189) para el deseo en los hijos, otro modo en que Freud conceptualizaba el complejo de Edipo. El padre de Dora la seduce con su deseo volcado sobre Frau K. La obra de Berman exhibe a un padre que confía su hija a alguien de quien desconfía y que parece perverso y corrupto. Freud había develado que los padres promueven el deseo entre sus hijos con sus deseos preferenciales, aunque también lo cercenan. De este modo, la madre mutila en la hija, tanto "voluntad" (p. 188) como libertad sexual. La otra escena de Berman da cuenta de este cercenamiento del cual el mismo Freud participaría. La madre de Dora, en tanto referente identificatorio desdeñable, habría cercenado en su hija el deseo de ser mujer. Serlo supone carecer de voluntad libre. Freud, en el drama teatral, se empeña en sacrificar también esta voluntad libre, en sacrificar su negativa a ser mujer, para curarse. Hacia el final de la obra, Dora toma el tren El Ave del Amanecer, para dirigirse a estudiar en la Universidad de Leipzig. En el trayecto de posible liberación se encuentra con Herr K. y la experiencia de la violación. También allí se le cortan las alas a la liberación de su deseo y su deseo de liberación. Tres Freud encaran a una adolescente que cuestiona e impugna el saber del Otro sobre su deseo y su sexo. Quizás porque la histeria le enseñó a Freud la condición escindida del sujeto. Dora conjuga alteridades tan sorprendentes que invitan a construir un escenario para su recreación, pues plasma de modo extasiado alteridades en conflicto. Si Dora admite haberle fallado a su padre, a Freud y a ella misma, en la medida en que advierte no sólo el odio hacia estos 
hombres erigidos como presuntos amos de su deseo, sino también hacia ella misma traicionando la causa de su deseo. Dora, desde el escenario de Berman, no habría sido consecuente con su deseo dirigido a Frau K. o en relación a su proyecto de formación universitaria.

La confluencia de Berman con Freud acerca de la condición textual de la transferencia nos permitió atisbar algo más allá del papel del odio y su correlato vindicativo. Nos referimos a otro sacrificio. Lo que parece ofrendarse como sacrificio es la dimensión asertiva de la verdad. También podría ser que Dora se disculpe en el texto de Berman con Freud por fallar en no ser tan genuina como le demandaba a él. Se disculpa por no permitir curarle, porque curarse quizás implicaba ser hipócrita, adaptándose y acomodándose al deseo del padre. Pero también sugiere que se culpa por engañarse a sí misma en su actitud complaciente en la relación entre su padre y Frau K, en ser cómplice gozosa de ese sacrificio, en esa falsedad de la cual participaba y se quejaba como, lo indica Lacan (1951/1990a), "alma bella" (p. 208). La experiencia clínica con la histeria condujo a Freud (1895/2006i) a problematizar la dimensión engañosa de la verdad relatada en el discurso de sus pacientes. Al grado de sostener la hipótesis de una "proton pseudos" (p. 400), primera falsedad, en el discurso histérico que plasma un montaje de doble escenario, apuntando a la revelación de la verdad guarecida en un aterrador recuerdo traumático. El escenario de alteridad que diseña Berman para Dora propone la compleja relación ficticia del sujeto con la verdad en sus anudamientos con el deseo, la sexualidad y el síntoma.

\section{Referencias}

Andreas-Salomé, L. (2013). El erotismo. México, MX: Colofón.

Berman, S. (2001). Feliz nuevo siglo doktor Freud. México, MX: La Centena.

Brun, D. (2013). L'insidieuse malfaisance du père. Paris, FR: Odile Jacob.

Corbin, A. (2005). La rencontre des corps. In A. Corbin, J.-J. Courtine, G. Vigarello, Histoire du corps 2. De la Révolution à la Gran Guerre. Paris, FR: Seuil.

Decker, H. S. (1999). Freud, Dora y la Viena de 1900. Madrid, ES: Biblioteca Nueva.

Ferenczi, S. (1984). Confusión de lenguas entre los adultos y el niño. In Sandor Ferenczi, Psicoanálisis IV. Madrid, ES: Espasa-Calpe.

Freud, S. (1999a). Studien über Hysterie (Vol. I). In Gesammelte Werke. Frankfurt am Main, GER: Fischer. (Trabajo original publicado en 1893-1895). 


\section{ARTIGOS}

Freud, S. (1999b). Zur Psychopathologie des Alltagslebens (Vol. IV). In Gesammelte Werke. Frankfurt am Main, GER: Fischer. (Trabajo original publicado en 1901).

Freud, S. (1999c). Bruschtück einer Hysterie - Analyse (Vol. V). In Gesammelte Werke. Frankfurt am Main, GER: Fischer. (Trabajo original publicado en 1901-1905).

Freud, S. (1999d). Massenpsychologie und Ich-Analyse (Vol. XVIII). In Gesammelte Werke. Frankfurt am Main, GER: Fischer. (Trabajo original publicado en 1921).

Freud, S. (2006a). Fragmentos de la correspondencia con Fliess (Vol. I). In Obras completas. Buenos Aires, AR: Amorrortu. (Trabajo original publicado en 1892-1899).

Freud, S. (2006b). La interpretación de los sueños (Vol. V). In Obras completas. Buenos Aires, AR: Amorrortu. (Trabajo original publicado en 1900).

Freud, S. (2006c). Análisis fragmentario de un caso de histeria (Dora) (Vol. VII). In Obras completas. Buenos Aires, AR: Amorrortu. (Trabajo original publicado en 1901-1905).

Freud, S. (2006d). Tres ensayos de teoría sexual (Vol. VII). In Obras completas. Buenos Aires, AR: Amorrortu. (Trabajo original publicado en 1905).

Freud, S (2006e). Las fantasías histéricas y su relación con la bisexualidad. In Obras Completas (Vol. IX). Buenos Aires, AR: Amorrortu. (Trabajo original publicado en 1908).

Freud, S. (2006f). Sobre la más generalizada degradación de la vida amorosa (Vol. XI). In Obras completas. Buenos Aires, AR: Amorrortu. (Trabajo original publicado en 1912).

Freud, S. (2006g). Introducción del narcisismo (Vol. XIV). In Obras completas. Buenos Aires, AR: Amorrortu. (Trabajo original publicado en 1914).

Freud, S. (2006h). Conferencias de introducción al psicoanálisis, El sueño (Vol. XV). In Obras completas. Buenos Aires, AR: Amorrortu. (Trabajo original publicado en 1915-16).

Freud, S. (2006i). Proyecto de psicología para neurólogos (Vol. III). In Obras completas. Buenos Aires, AR: Amorrortu. (Trabajo original publicado en 1895).

Graves, R., \& Patai, R. (2009). Los mitos hebreos. Madrid, ES: Alianza.

Isräel, L. (1979). Histeria, el sexo y el médico. Barcelona, ES: Toray-Masson.

Julien, P. (2002). Psicosis, perversión, neurosis. La lectura de Jacques Lacan. Buenos Aires, AR: Amorrortu.

Lacan, J. (1961-62). L'identification. Leçon du 20 décembre 1961. (Inédito).

Lacan, J. (1990a). Intervención sobre la Transferencia. In Escritos 1 (pp. 204-218).

México, MX: Siglo XXI. (Trabajo original publicado en 1951). 
Lacan, J. (1990b). El seminario. Libro 3. Las psicosis. Buenos Aires, AR: Paidós. (Trabajo original publicado en 1955-56).

Lacan, J. (1990c). El seminario. Libro 7. La Ética del psicoanálisis. Buenos Aires, AR: Paidós. (Trabajo original publicado en 1959-60).

Lacan, J. (1981). El seminario. Libro 1. Los escritos técnicos de Freud. Buenos Aires, AR: Paidós. (Trabajo original publicado en 1953-54).

Lacan, J. (1994). El seminario. Libro 4. La relación de objeto. Buenos Aires, AR: Paidós. (Trabajo original publicado en 1956-57).

Lacan, J. (1999). El seminario. Libro 5. Las formaciones del inconsciente. Buenos Aires, AR: Paidós (Trabajo original publicado en 1957-58).

Lacan, J. (2008). El seminario. Libro 10. La angustia. Buenos Aires, AR: Paidós. (Trabajo original publicado en 1962-63).

Lacan, J. (2013). El seminario. Libro 11. Los cuatro conceptos fundamentales del psicoanálisis. Buenos Aires, AR: Paidós. (Trabajo original publicado en 1964).

Lauru, D. (2015). De la haine de soi à la haine de l'autre. Paris, FR: Albin Michel.

Malcolm, J. (1981). Psychoanalysis: The impossible profession. New Jersey: Rowman \& Littlefield Publishers.

Mannoni, O. (1980). Ficciones freudianas. Madrid, ES: Fundamentos.

Pérez-Rincón, H. (1998). El teatro de las histéricas. De cómo Charcot, descubrió entre otras cosas, que también había histéricos. México, MX: Fondo de Cultura Económica.

Rodrigué, E. (1996). El siglo del psicoanálisis I. Buenos Aires, AR: Sudamericana.

Rosolato, G. (1979). La histeria. Estructuras psicoanalíticas. In J. J. Saurí, Las histerias. Buenos Aires, AR: Nueva Visión.

Stryckman, N. (2019). Le symptôme au service de deux maîtres? In A. Vanier, Figures de la psychanalyse. Logos\&Anankè, Paris, FR: Seuil, 37.

Torres, M. (1984). La histeria. In I. de Krell, La escucha, la histeria. Buenos Aires, AR: Paidós.

Velázquez, S. (2013). Violencias cotidiana, violencias de género. Escuchar, comprender, ayudar. Buenos Aires, AR: Paidós.

\section{Resumos}

(As verdades fictícias na outra cena de Dora)

O trabalho consiste em apresentar quatro posicionamentos de verdade fictícia procedente do drama de Sabina Berman, Feliz Nuevo Siglo, Doktor Freud, em torno 


\section{ARTIGOS}

do caso Dora, de Sigmund Freud. Dessa encenação, inerente à própria estrutura histérica, revelam-se os fantasmas da prostituição, da sedução do pai, da implantação da feminilidade e da diversidade textual da (contra)transferência. A obra leva a clínica a uma dimensão de debate crítico, no qual o próprio Freud encontra-se dividido entre as formulações de sua teoria da sexualidade e as questões inéditas que o testemunho da experiência única provoca. Não só a cortina das condições históricas e sociais que compreende um exercício da clínica da palavra e da subjetividade é aberta, mas daquelas que determinam as complexas relações entre os sexos e os paradigmas imaginário-ideológicos que têm impacto no pensamento de Freud.

Palavras-chave: Verdade-ficção, prostituição, sedução, feminilidade, transferência

(The fictional truths in the other scene of Dora)

This article discusses four different positions of fictional truth derived from Sabina Berman's play, Feliz Nuevo Siglo Doktor Freud, on Dora's clinical case. The staging inherent to the hysteric structure reveals the fantasies of prostitution, of the seduction of the father, of the instauration of femininity and of the textual diversity of (counter) transference. The play takes clinical work to a dimension of critical debate in which Freud finds himself divided between the different formulations of his sexual theory and the breakthroughs brought about by the testimony of the singular experience. It reveals not only the background of social and historical conditions that frame the clinical exercise of the word and subjectivity, but also the conditions that determine complex relations between sexes and imaginary-ideological schemes that influence Freud's thinking.

Key words: Fictional-truth, prostitution, seduction, feminity, transference

(Les verités fictives dans l'autre scène de Dora)

Cet article consiste à rendre compte de quatre positions de vérité fictive dérivées la pièce de Sabina Berman, Feliz Nuevo Siglo Doktor Freud, sur le cas de Dora, patiente traitée par Sigmund Freud. De cette mise en scène inhérente à la structure hystérique, se révèlent les fantômes de la prostitution, de la séduction du père, de l'établissement de la féminité et la diversité textuelle du (contre)transfert. La pièce mène la clinique vers une dimension de débat critique où Freud lui-même est partagé entre les formulations de sa théorie sexuelle et les questions inédites ce qui provoque le témoignage de l'expérience singulière. On révèle ainsi non seulement la toile de fond des conditions sociales et historiques qui encadrent une pratique clinique de la parole et de la subjectivité, mais aussi celles qui déterminent les relations complexes entre les sexes et les schémas imaginaires-idéologiques qui influencent la pensée de Freud.

Mots clés: Verité-fiction, prostitution, séduction, feminité, transfert 
Citação/Citation: Orozco-Guzmán, M., Soria-Escalante, H., \& Quiroz-Bautista, J. (2021, dezembro). Las verdades ficticias en la otra escena de Dora. Revista Latinoamericana de Psicopatologia Fundamental, 24(4), 586-613. http://dx.doi.org/10.1590/1415-4714.2021v$24 \mathrm{n} 4 \mathrm{p} 586.6$

Editora/Editor: Profa. Dra. Sonia Leite

Submetido/Submitted: 25.10.2020 / 10.25.2020 Aceito/Acepted: 18.5.2021 / 5.18.2021

Copyright: (C) 2009 Associação Universitária de Pesquisa em Psicopatologia Fundamental/ University Association for Research in Fundamental Psychopathology. Este é um artigo de livre acesso, que permite uso irrestrito, distribuição e reprodução em qualquer meio, desde que o autor e a fonte sejam citados / This is an open-access article, which permits unrestricted use, distribution, and reproduction in any medium, provided the original authors and sources are credited.

Financiamento/Funding: Este trabalho não recebeu apoio. / This work received no funding.

Conflito de interesses/Conflict of interest: Os autores declaram que não há conflito de interesses. / The authors declare that there is no conflict of interest.

\section{Mario Orozco-GuZmán}

Doctor en Psicología; Profesor-Investigador, Facultad de Psicología, Universidad Michoacana de San Nicolás de Hidalgo (Morelia, México).

Facultad de Psicología, UMNSH.

Gral. Francisco Villa 450, Dr Miguel Silva González

CP. 58110, Morelia, Michoacán, México

orguzmo@yahoo.com.mx

https://orcid.org/0000-0001-5365-9966

HADA Soria-Escalante (autora de correspondencia/ corresponding author)

Doctora en Psicología; Profesora-Investigadora, Escuela de Psicología, Universidad de Monterrey (México).

Universidad de Monterrey

Av. Ignacio Morones Prieto 4500 Pte

CP. 66238, San Pedro Garza García, Nuevo León, México.

hada.soria@udem.edu, hadasoria@gmail.com

https://orcid.org/0000-0003-0714-8924 


\section{ARTIGOS}

JeAnnet Quiroz-Bautista

Doctora en Psicología; Profesora-Investigadora, Facultad de Psicología, Universidad Michoacana de San Nicolás de Hidalgo (Morelia, México)

Facultad de Psicología, UMNSH.

Gral. Francisco Villa 450, Dr Miguel Silva González

CP. 58110, Morelia, Michoacán, México.

jeaquib@yahoo.com

https://orcid.org/0000-0002-7925-3785

This is an open-access article, which permits unrestricted use, distribution, and reproduction in any medium for non-commercial purposes provided the original authors and sources are credited. 